\title{
Energy conversion in 7-(Diethylamino)coumarin doped PMMA fluorescent fibre
}

\author{
Piotr Miluski $^{1}$ (D) Marcin Kochanowicz $^{1} \cdot$ Jacek Zmojda $^{1} \cdot$ \\ Dominik Dorosz ${ }^{2}$
}

Received: 11 January 2017/ Accepted: 1 March 2017/Published online: 9 March 2017

(C) The Author(s) 2017. This article is published with open access at Springerlink.com

\begin{abstract}
The article presents fabrication and spectroscopic characterization of 7-(Diethylamino)coumarin doped polymeric fibre. The poly(methyl methacrylate) (PMMA) was chosen as it assures direct doping possibility and excellent optical properties in fluorescence spectrum of used dye. The fabricated polymer exhibits an intense luminescence (at dye concentration $\left.1.2 \times 10^{-4} \mathrm{~mol} / \mathrm{l}\right)$ in the range 505-537 nm (exc. $405 \mathrm{~nm}$ ). Moreover, he coumarin doped PMMA fibre 600/1200 $\mu \mathrm{m}$ (doped core/cladding) fibre was fabricated and characterized. Presented fluorescence spectrum modification possibility can be used for new optical fibre construction optimization.
\end{abstract}

Keywords 7-(Diethylamino)coumarin · Polymeric optical fibre ·

Poly(methyl methacrylate) $\cdot$ Fluorescence $\cdot$ Organic dyes

Mathematic Subject Classification $160.4890 \cdot 160.2540 \cdot 160.5470$

\section{Introduction}

Photoluminescent complexes are wildly used in optical technology. The numerous applications of organic luminescent materials are well known in medicine (luminescent labeling, fluorescence-energy-transfer-based microscopy), environmental monitoring (water acidity and pollution) and numerous fields of scientific research (Resch-Genger et al. 2008; Basabe-Desmonts et al. 2007; Kasprzak et al. 2011; Lichtman and Conchello 2005; Lian et al. 2004; Merian et al. 2012; Rao et al. 2007). Fluorescent organic compounds (e.g. xanthenes, proteins, and polycyclic aromatic hydrocarbons) are wildly used due to their bright luminescence in the visible spectrum range (Miluski et al. 2015a; Johansson 1991;

Piotr Miluski

p.miluski@pb.edu.pl

1 Bialystok University of Technology, Wiejska 45D, 15-351 Białystok, Poland

2 AGH University of Science and Technology, 30 Mickiewicza Av., 30-059 Kraków, Poland 
Al-Hamdani et al. 2010). Moreover, their broadband absorption spectrum allows efficient excitation using arc lamp ( $\mathrm{Hg}, \mathrm{Xe})$, semiconductor LEDs, and laser diodes. Fluorescent molecules can be often incorporated into polymer structure without significant change their luminescent properties. In such circumstances, the rigid organic host gives an opportunity for new applications in optical fibre technology. The organic dyes can be incorporated in optical fibers based on thermoplastic polymers due to low drawing temperatures (much lower than used in optical glass technology). In fact, the poly(methyl methacrylate) is the most frequently used polymer for optical applications (Miluski et al. 2015b; Bilro et al. 2012). High transparency and well-developed processing technology of PMMA make it a good candidate for low-cost optical components and optical fibres fabrication (Miluski et al. 2016a, b). The step/gradient index and microstructured optical fibers can be fabricated using PMMA host (Miluski et al. 2016b; Tama et al. 2010; Bundalo et al. 2014; Kailasnatha et al. 2008; Oliveira et al. 2015; Huang et al. 2004; Barton et al. 2004). Moreover, the guiding properties of optical fibres can be used to obtain some specific advantages: optical signal amplification, amplified spontaneous emission (ASE), and energy transfer (Karimi et al. 2004; Dorosz et al. 2012; Arrue et al. 2011; Ayesta et al. 2011; Nihei et al. 1996). The optical amplifiers, sensors, and lasers based on fluorescent organic complexes were reported so far (Dorosz et al. 2012; Arrue et al. 2011; Ayesta et al. 2011; Nihei et al. 1996). The Stoke shift, mirror symmetry of absorption and emission spectra, high quantum yield and short lifetime (few ns) were reported in PMMA host doped by coumarins (Johansson 1991; Al-Hamdani et al. 2010; Kailasnatha et al. 2008). In fact, the coumarin derivatives are commonly used for optical fluorescence microscopy, OLEDs, and dye lasers (Achamma et al. 2002; Bangar Raju 1995; Donovalova et al. 2012; Hrdlovic et al. 2010). The proposed 7-(Diethylamino)coumarin doped PMMA fibre fabrication and fluorescence properties characterization is shown. Moreover, the reabsorption effect observed in optical fibre structure can be used for fluorescence spectrum modification.

\section{The fabrication of coumarin doped optical fibre}

The raw materials: monomer methyl methacrylate (MMA), Benzoyl Peroxide (BP), Butanediol (BT), and Benzyl Benzoate (BEN) were supplied by Sigma-Aldrich and used without further purification. The 7-(Diethylamino)coumarin $\left(\mathrm{C}_{13} \mathrm{H}_{15} \mathrm{NO}_{2}\right.$ formula) was supplied by TCI Company $(>98 \%)$. The stabilizer agent has been removed from the monomer before polymerization process. The free radical polymerization process was performed by $40 \mathrm{~h}$ at temperature $65-80{ }^{\circ} \mathrm{C}$. The optical preforms (presented in Fig. 1a, diameter $12 \mathrm{~mm}$ ) were fabricated as solid (A) and doped core/cladding structure (B). The used coumarin derivative concentration $\left(1.2 \times 10^{-4} \mathrm{~mol} / \mathrm{l}\right)$ was verified to obtain efficient luminescence in the polymeric host. No polymerization defects (cracklings, intrusions or bubbles) were observed in fabricated preforms. The slightly dissolved boundary of cladding part (core/cladding preform) was noticed after the polymerization. The preforms were drawn into the fibers $(0.4-2.0 \mathrm{~mm}$ diameter) using drawing tower. The step index (0.6/ $1.2 \mathrm{~mm}$ ) fibre is presented in Fig. $1 \mathrm{~b}$. 
(a)

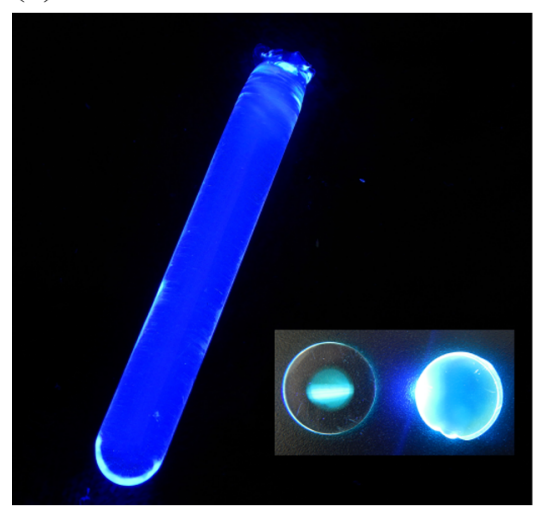

(b)

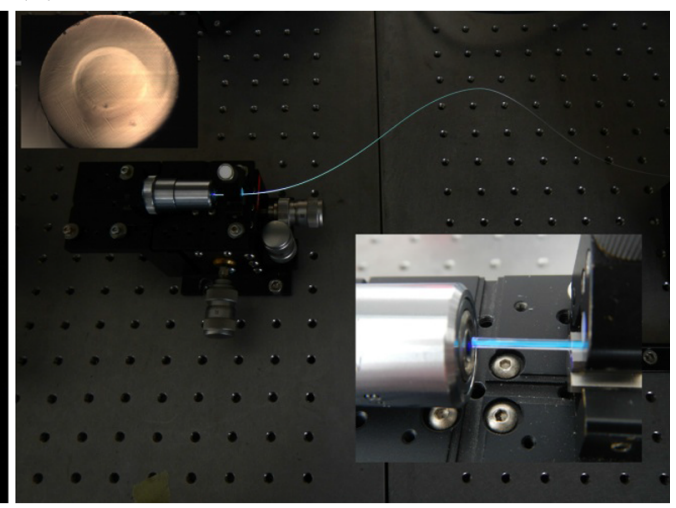

Fig. 1 The photo of fabricated: a preform A (at $365 \mathrm{~nm}$ excitation, mercury vapour black light), insertion: preform discs (from left: B and A, at exc. $405 \mathrm{~nm}$ ), b optical fibre at laser $405 \mathrm{~nm}$ one end excitation, insertion: cross section of fibre, side emission of fabricated fibre

\section{Measurements}

The properties of 7-(Diethylamino)coumarin doped PMMA preforms (excitation and fluorescence spectra) and fibers (fluorescence, attenuation) were characterized. The specimens were cut and polished into the $2.0 \mathrm{~mm}$ thick preform discs. The refractive index (1.4925 and 1.4917 for core and cladding part respectively) was verified at $633 \mathrm{~nm}$ using optical refractometer (Metricon). The excitation spectrum was measured using Horiba Fluorolog 3 spectrofluorometer equipped with a Xenon arc lamp $(450 \mathrm{~W})$. The fluorescence spectra were recorded using Stellarnet Green Wave spectrometer in the range of $350-900 \mathrm{~nm}$ and $0.5 \mathrm{~nm}$ resolution. Additionally, the fluorescence of bulk specimens was measured using integrating sphere (120 mm diameter). The obtained excitation and fluorescence spectra are presented in Fig. 2. Efficient excitation can be obtained for $320-420 \mathrm{~nm}$ spectral range. The fluorescence spectrum of 7-(Diethylamino)coumarin (Fig. 2b) exhibits two peaks at 453 and $496 \mathrm{~nm}(\mathrm{FWHM}=110 \mathrm{~nm})$.

(a)

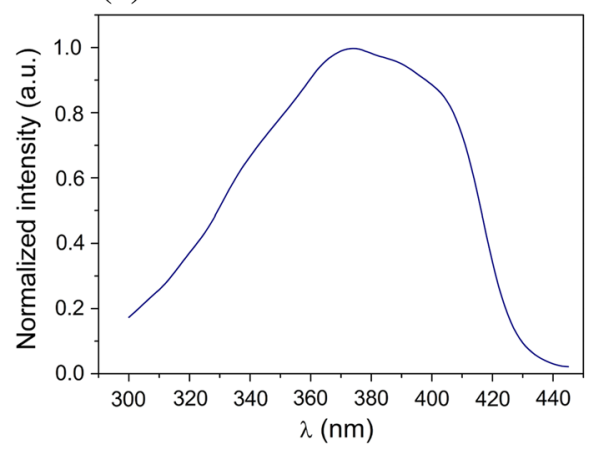

(b)

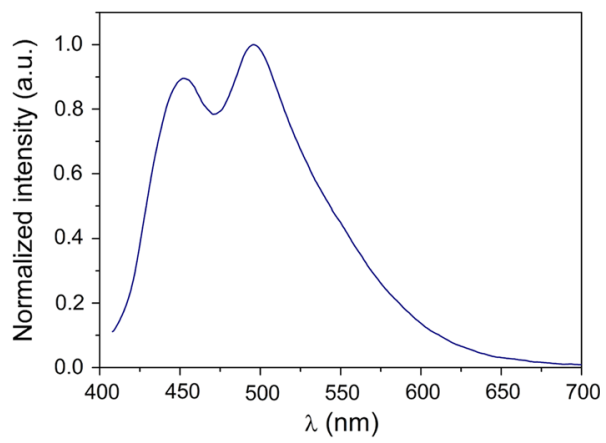

Fig. 2 The optical properties of 7-(Diethylamino)coumarin doped PMMA: a excitation spectrum, monitoring at $450 \mathrm{~nm}$, b fluorescence spectrum, excitation at $405 \mathrm{~nm}$ 
The laser diode ( $405 \mathrm{~nm}, 200 \mathrm{~mW}$ ) was used for excitation of fabricated optical fibres. The polymeric fibres measurements were carried out using one end excitation and cutback method in the fibre length range 50-500 $\mathrm{mm}$. Additionally, the dopant distribution profile was measured for preform disc (B) and is presented in Fig. 3. It is noticeable that dissolving process of core-cladding boundary determines the final dopant distribution profile.

The single luminescence peak (Fig. 4a) observed in optical fibres is resulted by reabsorption effect in optical fibre structure (the peak observed at $453 \mathrm{~nm}$ in bulk sample is strongly absorbed in optical fibre structure). Additionally, the fluorescence spectrum shows so-called "red shift" phenomenon versus the fibre length. The effective pumping length was estimated to $45 \mathrm{~mm}$ (at $2 \%$ initial power criterion). The reabsorption of coumarin dye leading to strong fluorescence signal attenuation (slope $16 \mathrm{~dB} / \mathrm{m}$, Fig. $4 \mathrm{~b}$ ) and limits the useful fiber length to few tenths of centimeters.

Additionally, the $\lambda_{\max }$ and FWHM plots versus fibre length are presented in Fig. 5. The monotonic $\lambda_{\max }$ increasing tendency is clearly visible $(505-537 \mathrm{~nm}$, average slope $0.7 \mathrm{~nm} /$ $\mathrm{cm}$ ) for fibre length 50-500 mm (Fig. 5a). The increasing of FWHM (from 77 up to $108 \mathrm{~nm}$ ) is possible since reabsorption effects are much weaker for the right tail of fluorescence spectrum.

The proposed 7-(Diethylamino)coumarin doped optical fibre exhibit interesting optical properties. The fluorescence (FWHM, $\lambda_{\max }$ ) can be optimized by the energy conversion process in polymeric optical fibre. The possibility of fluorescent spectrum shape modification can be used in new constructions of light sources based on direct energy conversion in polymeric optical fibres.

\section{Summary}

The 7-(Diethylamino)coumarin doped $\left(1.2 \times 10^{-4} \mathrm{~mol} / \mathrm{l}\right)$ optical fibre was presented. The efficient luminescence was observed at $405 \mathrm{~nm}$ excitation. The measured absorbance and fluorescence spectra are presented. Moreover, the fluorescence spectrum shape parameters

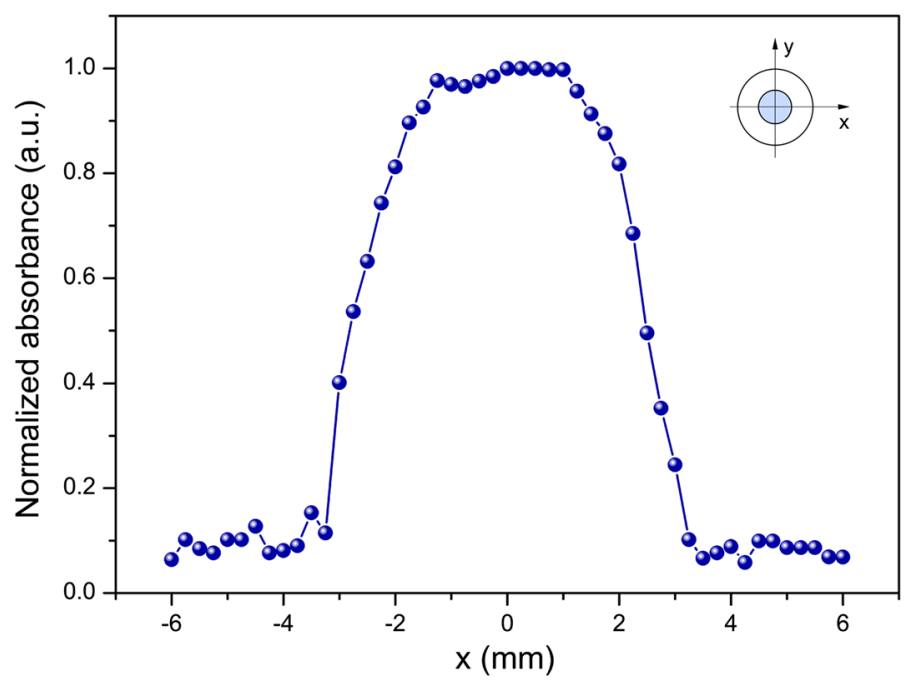

Fig. 3 Normalized absorbance profile of preform B measured at $\lambda=405 \mathrm{~nm}$ 
(a)

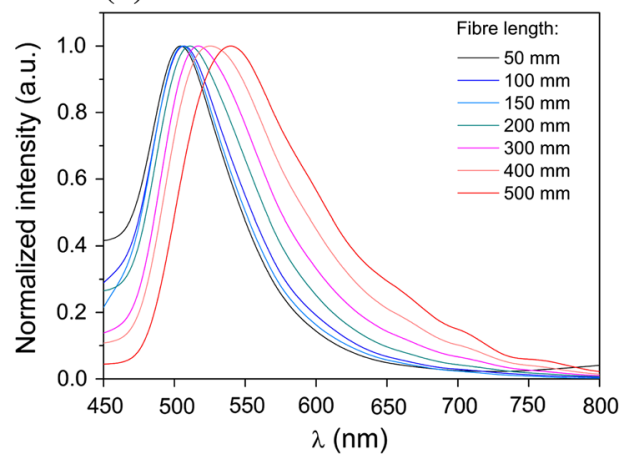

(b)

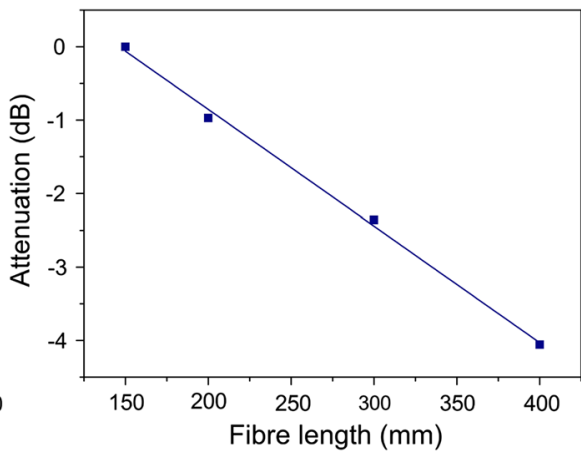

Fig. 4 a The fluorescence spectrum versus optical fibre length (B), at $405 \mathrm{~nm}$, b fluorescence signal attenuation at $\lambda_{\max }$
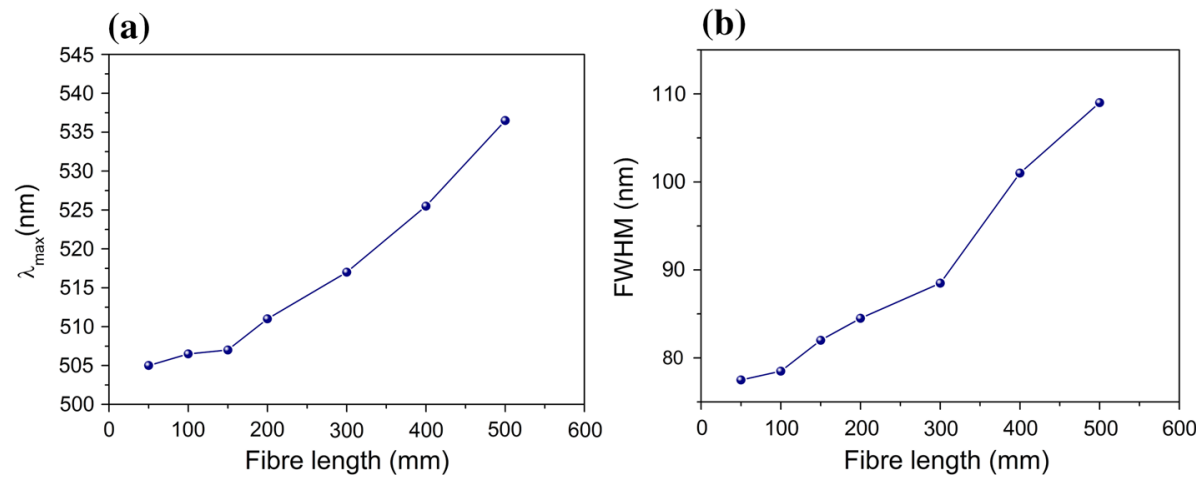

Fig. 5 a The $\lambda_{\max }$ versus fibre (A) length, b The FWHM versus fibre (A) length, both graphs at $405 \mathrm{~nm}$, $150 \mathrm{~mW}$

(FWHM, $\lambda_{\max }$ ) were measured for fabricated optical fibre and the reabsorption effect in optical fibre is presented. The 7-(Diethylamino)coumarin doped PMMA optical fibre can be used for new fibre optic light sources and optical amplifiers investigations.

Acknowledgements The authors are grateful to Jan Mrazek from Institute of Photonics and Electronics of the Czech Academy of Sciences for help in excitation spectra measurements. This work was supported by Project No. S/WE/4/2013.

Open Access This article is distributed under the terms of the Creative Commons Attribution 4.0 International License (http://creativecommons.org/licenses/by/4.0/), which permits unrestricted use, distribution, and reproduction in any medium, provided you give appropriate credit to the original author(s) and the source, provide a link to the Creative Commons license, and indicate if changes were made.

\section{References}

Achamma, K., Nibu, A.G., Binoy, P., Nampoori, V.P.N., Vallabhan, C.P.G.: Studies on fluorescence efficiency and photodegradation of Rhodamine 6G doped PMMA using a dual beam thermal lens technique. Laser Chem. 20, 99-110 (2002) 
Al-Hamdani, A.H., Al-Ethawi, A.S., Al-Hamdani, R.: Fluorescence efficiency of Rhodamine 6G doped PMMA. J. Mater. Sci. Eng. 4, 57-61 (2010)

Arrue, J., Jimenez, F., Ayesta, I., Asuncion Illarramendi, M., Zubia, J.: Polymer-optical-fiber lasers and amplifiers doped with organic dyes. Polymers 3, 1162-1180 (2011)

Ayesta, I., Arrue, J., Jiménez, F., Asuncion Illarramendi, M., Zubia, J.: Analysis of the emission features in graded-index polymer optical fiber amplifiers. J. Lightwave Technol. 29, 2629-2635 (2011)

Bangar Raju, B.: Photophysical properties and energy transfer dye laser characteristics of 7-Diethylamino-3Heteroaryl coumarin in solution. Laser Chem. 16, 109-120 (1995)

Barton, G., Eijkelenborg, M.A., Henry, G., Large, M.C.J., Zagari, J.: Fabrication of microstructured polymer optical fibres. Opt. Fiber Technol. 10, 325-335 (2004)

Basabe-Desmonts, L., Reinhoudt, D.N., Crego-Calama, M.: Design of fluorescent materials for chemical sensing. Chem. Soc. Rev. 36, 993-1017 (2007)

Bilro, L., Alberto, N., Pinto, J.L., Nogueira, R.: Optical sensors based on plastic fibers. Sensors 12, 12184-12207 (2012)

Bundalo, I.L., Nielsen, K., Markos, C., Bang, O.: Bragg grating writing in PMMA microstructured polymer optical fibers in less than 7 minutes. Opt. Express 22, 5270-5276 (2014)

Donovalova, J., Cigan, M., Stankovicova, H., Gaspar, J., Danko, M., Gaplovsky, A., Hrdlovic, P.: Spectral properties of substituted coumarins in solution and polymer matrices. Molecules 17, 3259-3276 (2012)

Dorosz, D., Dorosz, J., Zajac, A., Zmojda, J., Kochanowicz, M.: Active optical fibres for application in laser and broadband ASE sources. Bull. Pol. Acad. Sci. 60, 673-682 (2012)

Hrdlovic, P., Donovalova, J., Stankovicova, H., Gaplovsky, A.: Influence of polarity of solvents on the spectral properties of bichromophoric coumarins. Molecules 15, 8915-8932 (2010)

Huang, Y., Xu, Y., Yariv, A.: Fabrication of functional microstructured optical fibers through a selectivefilling technique. Appl. Phys. Lett. 85, 5182-5184 (2004)

Johansson, L.B.A.: Spectroscopic studies of fluorescent perylene dyes. Spectrochim. Acta 4IA, 857-861 (1991)

Kailasnatha, M., Sreejaya, T.S., Kumar, R., Vallabhan, C.P.G., Nampooria, V.P.N., Radhakrishnana, P.: Fluorescence characterization and gain studies on a dye-doped graded index polymer optical-fiber preform. Opt. Laser Technol. 40, 687-691 (2008)

Karimi, M., Granpayeh, N., Morraveg Frshi, M.K.: Analysis and design of a dye-doped polymer optical fiber amplifier. Appl. Phys. B 78, 387-396 (2004)

Kasprzak, J., Samsel, D., Borkowska, A., Kecik, M.: Optical diagnostic in medicine-needs and possibilities. Acta Phys. Pol. A 120, 678-685 (2011)

Lian, W., Litherland, S.A., Badrane, H., Tan, W., Wu, D., Baker, H.V., Gulig, P.A., Lime, D.V., Jin, S.: Ultrasensitive detection of biomolecules with fluorescent dye-doped nanoparticles. Anal. Biochem. 334, 135-144 (2004)

Lichtman, J.W., Conchello, J.A.: Fluorescence microscopy. Nat. Methods 2, 910-919 (2005)

Merian, J., Gravier, J., Navarro, F., Texier, I.: Fluorescent nanoprobes dedicated to in vivo imaging: from preclinical validations to clinical translation. Molecules 17, 5564-5591 (2012)

Miluski, P., Dorosz, D., Kochanowicz, M., Zmojda, J., Dorosz, J.: The xanthene dyes doped PMMA microspheres for optical sensors applications. Proc. SPIE 9816, 981607 (2015a)

Miluski, P., Dorosz, D., Zmojda, J., Kochanowicz, M., Dorosz, J.: Luminescent polymer optical fibre sensor for temperature measurement. Acta Phys. Pol. A 127, 730-733 (2015)

Miluski, P., Dorosz, D., Kochanowicz, M., Zmojda, J.: Fluorescent polymeric optical fibre illuminator. Electron. Lett. 52, 1550-1552 (2016a)

Miluski, P., Kochanowicz, M., Żmojda, J., Dorosz, D.: Emission properties and energy transfer in PeryleneRhodamine 6 G co-doped polymeric fiber. Chin. Opt. Lett. 14(12), 121602-121607 (2016b)

Nihei, E., Ishigure, T., Koike, Y.: High-bandwidth, graded-index polymer optical fiber for near-infrared use. Appl. Opt. 35, 7085-7090 (1996)

Oliveira, R., Bilro, L., Nogueira, R.: Smooth end face termination of microstructured, graded-index, and step-index polymer optical fibers. Appl. Opt. 54, 5629-5633 (2015)

Rao, J., Dragulescu-Andrasi, A., Yao, H.: Fluorescence imaging in vivo: recent advances. Curr. Opin. Biotechnol. 18, 17-25 (2007)

Resch-Genger, U., Grabolle, M., Cavaliere-Jaricot, S., Nitschke, R., Nann, T.: Quantum dots versus organic dyes as fluorescent labels. Nat. Methods 5, 763-775 (2008)

Tama, H.Y., Pun, C.-F.J., Zhou, G., Cheng, X., Tse, M.L.V.: Special structured polymer fibers for sensing applications. Opt. Fiber Technol. 16, 357-366 (2010) 